\title{
THE ROLE OF UMBILICAL CORD THICKNESS AND GLYCATED HEMOGLOBIN (HBA1C) LEVELS FOR PREDICTION OF FETAL MACROSOMIA IN PATIENTS WITH GESTATIONAL DIABETES MELLITUS
}

\author{
By \\ Mahmoud Fayez Mohamed Fathi, Taher Mohammed Moustafa, and \\ Ibrahim Ramadan Alsawy Rady \\ Department of Obstetrics and Gynecology, Faculty of Medicine, Al-Azhar University \\ E-mail: $\underline{\text { mahmoud.fayez66@gmail.com }}$
}

\begin{abstract}
Background: Diabetes with pregnancy is a known clinical risk factor associated with fetal macrosomia. The rationale for performing an elective cesarean section includes a potential reduction in perinatal complications, especially those related to macrosomia.

Objective: This study aimed to assess the accuracy of Glycated hemoglobin (HbA1c) and umbilical cord thickness in prediction of fetal macrosomia in diabetic pregnant women.

Patients and methods: The study included 100 diabetic pregnant, 27 - 28 weeks gestation, gathered from Inpatients and Obstetric Outpatient Clinic of Bab Alshariya University Hospital during the period between November 2018 and August 2019, attending for routine antenatal care.

Results: At a criterion of $>211 \mathrm{~mm} 2$, the umbilical cord area measured at $27-28$ weeks of gestation was able to predict high birth weight (macrosomia), with a sensitivity of $90.5 \%$ and a specificity of $91.7 \%$. The area under the curve for the receiver operating characteristic (ROC) was 0.9294 , with a $95 \%$ confidence interval of 0.8608 to 0.9702 , which was found to be statistically significant. When compared the ROC curves of both the umbilical cord area and the glycated hemoglobin, it was found that umbilical cord area was more reliable in predicting fetal macrosomia at the right criterion, the difference between the predictive efficiency for both parameters was found to be statistically significant.

Conclusion: Macrosomia is a cause of the worst of obstetric emergencies such as shoulder dystocia, birth asphyxia and postpartum haemorrhage. Shoulder dystocia cannot always be predicted accurately. However, predicting macrosomia can help to identify the population at risk of such complications.
\end{abstract}

Keywords: Umbilical cord thickness, Glycated hemoglobin (HbA1c), Macrosomia, Gestational diabetes mellitus.

\section{INTRODUCTION}

The umbilical cord is responsible for maternal-fetal blood flow. Normally, it is composed of two arteries permeated with venous blood and a vein that transports arterial blood, cushioned by a special type of mucous connective tissue known as
Wharton's jelly (WJ) and by remnants of the allantoides (Marino et al., 2019).

Reported risk factors of macrosomia are body mass index (BMI) before pregnancy, gestational weight gain, gestational diabetes mellitus (GDM), mother's age and gender (He et al., 2015). 
GDM is associated with many adverse pregnancy outcomes such as macrosomia and CS delivery (Barakat et al., 2010). At the same time macrosomia is a wellknown indicator of maternal diabetes in fetus which is strongly associated with prematurity, respiratory distress syndrome, birth trauma, fetal death and adverse maternal outcome (Yessoufou and Moutairou., 2011). Obesity in pregnancy is also recognized as a risk factor for many maternal and neonatal adverse outcomes including macrosomia, increased rate of cesarean section (CS), preeclampsia and gestational diabetes (GDM) (Athukorala et al., 2010). In addition, the placenta, as the interface between mother and fetus, is central to prenatal growth control. The fetus is dependent upon the placenta for its supply of nutrients and oxygen from the mother. Previous research found that the placental weights in the macrosomic fetuses were significantly higher than those with normal weight and placental weight was positively correlated with birth weight (Zhang et al., 2015). Fetal macrosomia is associated with a higher frequency of operative deliveries, post-partum hemorrhages, birth injury during vaginal delivery and neonatal hypoglycemia. Known maternal risk factors are only identified in $40 \%$ of women who deliver macrosomic babies (Auger et al., 2013). Macrosomia has been suggested as one of the possible risk factors for obesity in many studies (Mandal et al., 2011).

Diabetes represents a major public health concern and efforts to control hyperglycemia are an important element of the management of patients with type 2 diabetes. Hyperglycaemia is measured using hemoglobin A1c (HbA1c) test, which assesses the average level of blood glucose in the preceding 60-120 days. For diabetic patients an $\mathrm{HbA} 1 \mathrm{c}$ target of $6.5 \%$ (48 $\mathrm{mmol} / \mathrm{mol}$ ) is recommended (International Diabetes Federation, 2013).

Gestational diabetes mellitus (GDM) affects $2-6 \%$ of pregnant women and is associated with increased risk of important adverse perinatal outcomes, including macrosomia and birth injury (Beta et al., 2019). Therefore, for the prevention of traumatic birth and adverse outcomes, many studies have been performed for predicting birth weight accurately. Through the accurate prediction of macrosomic fetuses that have risk of traumatic birth, the route of delivery may be changed. Ultrasoundbased birth weight prediction is still insufficient. Investigators have attempted to improve ultrasound-based prediction of fetal macrosomia by various methods, such as the assessment of fat deposition at different locations. None of these methods have gained wide popularity because of the inability to accurately estimate fetal weight against conventional biometric formulas (Elessawy et al., 2017).

Studies that have assessed umbilical cord components to predict fetal weight have shown that there is a correlation between umbilical cord diameter, area and fetal biometric parameters (Cordero et al., 2015). In addition, some observers have suggested that combination of these two methods should give more reliable results for estimating macrosomic fetuses (Birol et al., 2012). 


\section{PATIENTS AND METHODS}

Setting: Bab Alshariya Hospital, AlAzhar University.

Duration: during the period between November 2018 to August 2019.

Design: Prospective - observational study to assess the accuracy.

Population: The study included 100 diabetic pregnant, 27 - 28 weeks gestation, gathered from Obstetric Inpatients and Outpatient Clinic of Bab Alshariya University Hospital attending for routine antenatal care. The required sample size has been calculated using IBM@ Sample Power@ version 3 (IBM@ Corp., Armonk, NY).

Diagnostic criteria of gestational diabetes mellitus:

1. Fasting plasma glucose level $126 \mathrm{mg} / \mathrm{dl}$ ( $7.0 \mathrm{mmol} / \mathrm{l})$.

2. Random plasma glucose level 200 $\mathrm{mg} / \mathrm{dl}(11.0 \mathrm{mmol} / \mathrm{l})$.

3. $\mathrm{HbA} 1 \mathrm{C} 6.5 \%$.

\section{All included women after informed} consent was subjected to:

a. Full history taking including personal, menstrual and past history.

b. Calculation of gestational age was based on the date of their last reliable menstrual period according to Naegele's rule and confirmed by ultrasound examination within the first trimester.

c. Abdominal examination to assess the fundal height and estimated fetal weight.

d. Ultrasound examinations were performed with a Medison RS 3.7-mHz
Convex transabdominal probe to measure umbilical cord thickness at 2728 weeks gestation and repeated at 3637 weeks gestation.

e. Ultrasonographic examination included fetal anthropometric parameters, biparietal diameter (BPD), femur length (FL) and estimated fetal weight (EFW), which were calculated automatically according to Hadlock's formula.

f. HbA1c levels were measured at $27-28$ weeks and at full term. Measuring HbA1c can reveal as to how high the blood glucose has been on an average, over the past 8-12 weeks.

A normal non-diabetic HbA1c value is $3.5-5.5 \%$. In diabetics, range of $6.5 \%$ to $7 \%$ is good. In individuals with poorly controlled diabetes, the quantity of this Glycated $\mathrm{Hb}$ is much higher than in healthy people (Kuenen et al., 2011).

g. Macrosomia was considered when estimated fetal weight is over 4,000 gm.

h. Follow up of the patients at birth included mode of delivery, birth weight and fetal sex.

i. Population variability included age, BMI, parity, mode of delivery, estimated birth weight by ultrasound, birth weight, HbA1c and umbilical cord thickness.

\section{Inclusion criteria:}

Pregnant women with:

1. 27 - 28 weeks gestation

2. Diabetes mellitus

3. Singleton gestation 
4. Normal umbilical morphology (two arteries and one vein).

\section{Exclusion criteria:}

1. The presence of fetal congenital anomalies

2. Multifetal pregnancy

3. Pregestational diabetes mellitus

4. Maternal chronic diseases (hypertension, renal disease, cardiac and pulmonary disease, etc.).

5. Patients with a diagnosis such as placenta previa, oligohydraminous, preeclampsia and intrauterine growth restriction.

6. Smoking or alcohol consumption during pregnancy.

7. Preterm delivery

The hospital Ethics Committee approved the study: The population sample under study was instructed about research protocol and signed informed consents were taken from each woman before inclusion in the study.

\section{Statistical methods}

Data were collected, tabulated, then analyzed using IBM $\odot$ SPSS $\odot$ Statistics version 22 (IBM c Corp., Armonk, NY). Normally distributed numerical data was presented as mean and SD and skewed data as median and interquartile range. Qualitative data was presented as number and percentage. Comparison of normally distributed numerical data was done using the unpaired student t-test. Skewed data was compared using Mann-Whitney U test. Categorical data were compared using Chi-squared test, or Fisher's exact test when appropriate. Receiver-operating characteristic (ROC) curve analysis was used to examine the value of the umbilical cord thickness or HbAlc level for prediction of fetal macrosomia. A twosided $p$-value less than 0.05 were considered statistically significant. This sample size had a power of $91 \%$ (type II error, 0.09) to detect statistical significance for a difference of 0.25 between a null area under the ROC curve (AUROC) of 0.5 and an alternative AUROC of 0.75 associated with the umbilical cord thickness or HbA1c level. An AUROC of 0.75 has been chosen as it is considered to be the least AUROC for a diagnostic/predictive test to be clinical relevance.

This calculation used a two-sided $\mathrm{z}$ test with a confidence level of $99 \%$ (type I error, 0.01).

\section{RESULTS}

The primary outcome was the feasibility of prediction of fetal macrosomia using umbilical cord area (thickness) and the Glycated hemoglobin (HbA1c) level.

The maternal age did not differ significantly between both groups, most of them were between 20 and 30 years of age
(36\%, 39\%, respectively), However, almost one-third of group (2) women were above 30 years of age $(31-35$ years; $25 \%$, respectively), however, still no significant difference was noted when compared the proportions in the two groups. Group (1) had a mean maternal age of $26.6 \pm 4.4$ years, group (2) had a 
mean maternal age of $27.1 \pm 3.8$ years and the total sample had a mean maternal age of $27.2 \pm 4.1$ years old. As regards the gravidity, both groups differed significantly where group (1) subjects/women had a mean of $3.6 \pm 1.3$ against $2.5 \pm 1.2$ for group (2) subjects/women, however, both group did not differ in parity. Macrosomic group had a higher proportion of female sex fetuses (60\%) against $40 \%$ male fetuses and non-macrosomic group showed $44 \%$ males and $56 \%$ females. however, when compared males and females proportion against each group did not differ significantly. Among the 15 patients who delivered macrosomic fetus, 5 women $(33 \%)$ were obese, 8 (54\%) were overweight and $2(13 \%)$ were normal. As regards the gestational age at delivery, the total sample had a mean gestational age $37.1 \pm 1.2$ weeks. In comparing both groups regarding the number of deliveries at full term and post-term, no statistically significant difference was found. However, both groups differed in the birth weight of the delivered fetuses, group 1 had a mean birth weight of $3924.9 \pm 418.3$ gm (for 15 fetuses) versus $3332.3 \pm 296.1$ gm (for 85 fetuses), which was highly significant $(\mathrm{p}<0.0001)$. Moreover, due to large baby size, both subgroups differed significantly as regards the mode of delivery, where $74 \%$ of group (1) women delivered by cesarean section against $42 \%$ of group (2) women (Table 1).

Table (1): Comparison between both groups as regards the baseline parameters/ characteristics

\begin{tabular}{|c|c|c|c|c|c|}
\hline \multicolumn{2}{|c|}{ Parameters Groups } & $\begin{array}{c}\text { Group 1: } \\
\text { Macrosomic } \\
\text { fetuses } \\
(\mathbf{n}=\mathbf{1 5}) \\
\text { Mean } \pm \text { SD } \\
\end{array}$ & $\begin{array}{c}\text { Group 2: } \\
\text { Non- } \\
\text { Macrosomic } \\
\text { fetuses } \\
(\mathbf{n}=85) \\
\end{array}$ & P-value & $\begin{array}{c}\text { Total } \\
\text { sample } \\
(\mathrm{n}=100)\end{array}$ \\
\hline \multirow{4}{*}{$\begin{array}{l}\text { Maternal } \\
\text { age } \\
\text { (years) }\end{array}$} & & $26.6 \pm 4.4$ & $27.1 \pm 3.8$ & .65 & $27.2 \pm 4.1$ \\
\hline & $20-25$ & $5(33 \%)$ & $29(34 \%)$ & \multirow{3}{*}{0.85} & $36(36 \%)$ \\
\hline & $26-30$ & $7(47 \%)$ & $34(40 \%)$ & & $39(39 \%)$ \\
\hline & $31-35$ & $3(20 \%)$ & $22(26 \%)$ & & $25(25 \%)$ \\
\hline \multicolumn{2}{|c|}{ Gravidity } & $3.6 \pm 1.3$ & $2.5 \pm 1.2$ & 0.01 & $3.0 \pm 1.1$ \\
\hline \multicolumn{2}{|c|}{ Parity } & $3.0 \pm 1.4$ & $2.7 \pm 1.2$ & 0.2 & $2.3 \pm 1.2$ \\
\hline \multirow{2}{*}{ Fetal sex } & Male & $6(40 \%)$ & $38(45 \%)$ & 0.7 & $44(44 \%)$ \\
\hline & Female & $9(60 \%)$ & $47(55 \%)$ & 0.62 & $56(56 \%)$ \\
\hline \multirow{3}{*}{$\begin{array}{l}\text { Body } \\
\text { mass } \\
\text { index } \\
(\mathrm{BMI})\end{array}$} & $19-24.9$ & $2(13 \%)$ & $45(53 \%)$ & \multirow{3}{*}{$<0.002$} & $47(47 \%)$ \\
\hline & $25-29.9$ & $8(54 \%)$ & $34(40 \%)$ & & $42(42 \%)$ \\
\hline & $\geq 30$ & $5(33 \%)$ & $6(7 \%)$ & & $11(11 \%)$ \\
\hline \multirow{3}{*}{$\begin{array}{c}\text { GA at } \\
\text { delivery } \\
\text { (Weeks) }\end{array}$} & & $36.1 \pm 2.2$ & $36.9 \pm 1.7$ & & $37.1 \pm 1.2$ \\
\hline & $34-40$ & $13(95 \%)$ & $78(92 \%)$ & 0.52 & $91(91 \%)$ \\
\hline & $>40$ & $2(5 \%)$ & $7(8 \%)$ & & $9(9 \%)$ \\
\hline \multicolumn{2}{|c|}{ Birth weight (gm) } & $\begin{array}{c}3924.9 \pm \\
418.3 \\
\end{array}$ & $\begin{array}{c}3332.3 \pm \\
296.1 \\
\end{array}$ & $<0.001$ & $\begin{array}{c}3418.3 \pm \\
378.2 \\
\end{array}$ \\
\hline \multirow{2}{*}{$\begin{array}{l}\text { Mode of } \\
\text { delivery }\end{array}$} & $\begin{array}{c}\text { Cesarean } \\
\text { Section }\end{array}$ & $11(74 \%)$ & $36(42 \%)$ & $<0.03$ & $47(47 \%)$ \\
\hline & $\begin{array}{l}\text { Vaginal } \\
\text { Delivery }\end{array}$ & $4(26 \%)$ & $49(58 \%)$ & & $53(53 \%)$ \\
\hline
\end{tabular}


As regards the glycated hemoglobin, both groups did not differ significantly when compared at $27-28$ weeks of gestation, where subgroup 1 had a mean HbA1c of $6.1 \pm 0.2 \%$ vs $6.3 \pm$ $0.3 \%$ for subgroup 2 , while the total sample had a mean of $6.2 \pm 0.4 \%$. At $36-$ 37 weeks of gestation, we found that group 1 had a higher HbA1c levels than group $2(6.4 \pm 0.3 \%$ vs $5.8 \pm 0.4 \%$, respectively), which was statistically significant $(p<0.0001)$, while the total sample had a mean of $6.1 \pm 0.3 \%$.
Both subgroups differed significantly as regards the umbilical cord area, group 1 had a mean UCA of $213.1 \pm 2.8 \mathrm{~mm}^{2}$ at $27-28$ weeks of gestation against 204.2 $\pm 2.1 \mathrm{~mm}^{2}$ for group 2. While the total sample had a mean UCA of $209.1 \pm 3.2$ $\mathrm{mm}^{2}$. At $36-37$ weeks of gestation, the total sample had a mean UCA of $219.1 \pm$ $6.8 \mathrm{~mm}^{2}$. Group (1) had a mean of $232.1 \pm$ $3.1 \mathrm{~mm}^{2}$ against $215.4 \pm 4.3 \mathrm{~mm}^{2}$ for group (2) (Table 2).

Table (2): Comparison between both groups as regards the glycated hemoglobin levels (HbA1c \%), and the umbilical cord area (UCA mm2), measured at $27-28$ weeks and $36-37$ weeks of gestation

\begin{tabular}{|c|c|c|c|c|c|}
\hline \multicolumn{2}{|c|}{ Parameters } & $\begin{array}{c}\text { Group 1 } \\
\text { Macrosomic } \\
\text { fetuses } \\
(\mathrm{n}=15)\end{array}$ & $\begin{array}{c}\text { Group } 2 \\
\text { Non- } \\
\text { macrosomic } \\
\text { fetuses } \\
(\mathrm{n}=85)\end{array}$ & P-value & $\begin{array}{c}\text { Total } \\
\text { sample } \\
(\mathrm{n}=100)\end{array}$ \\
\hline \multirow{2}{*}{$\begin{array}{l}\mathrm{HbA1c} \\
(\%)\end{array}$} & $\begin{array}{l}\text { 27- } 28 \text { Weeks } \\
\text { of Gestation }\end{array}$ & $6.1 \pm 0.2$ & $6.3 \pm 0.3$ & 0.02 & $6.2 \pm .4$ \\
\hline & $\begin{array}{c}\text { 36- } 37 \text { Weeks } \\
\text { of Gestation }\end{array}$ & $6.4 \pm 0.3$ & $5.8 \pm 0.4$ & $<0.0001$ & $6.1 \pm 0.3$ \\
\hline \multirow{2}{*}{$\begin{array}{l}\text { UCA } \\
\left(\mathrm{mm}^{2}\right)\end{array}$} & $\begin{array}{c}\text { 27- } 28 \text { Weeks } \\
\text { of Gestation }\end{array}$ & $213.1 \pm 2.8$ & $204.2 \pm 2.1$ & $<0.0001$ & $209.1 \pm 3.2$ \\
\hline & $\begin{array}{c}\text { 36- } 37 \text { Weeks } \\
\text { of Gestation }\end{array}$ & $232.1 \pm 3.1$ & $215.4 \pm 4.3$ & $<0.0001$ & $219.1 \pm 6.8$ \\
\hline
\end{tabular}

When correlated the birth weight to the umbilical cord area in group 1 (Macrosomic fetuses), it was found that there was a strong, dependent and positive (direct) correlation between both parameters, either measurement at $27-28$ weeks or measurement at $36-37$ weeks of gestation $(r=0.7340 \& \quad 0.7483$, respectively). Moreover, these correlations were found to be statistically highly significant $(\mathrm{p}=0.0002 \& 0.0001$, respectively). The glycated hemoglobin neither had a strong nor significant correlation with the birth weight, neither measurement at 27- 28 weeks nor measurement at 36- 37 weeks of gestation (Table 3). 
THE ROLE OF UMBILICAL CORD THICKNESS AND GLYCATED...

Table (3): Relationship between birth weight (gm), the umbilical cord area (UCA mm2) , and the glycated hemoglobin (HbA1c \%) measured at 27 - 28 weeks and $36-37$ weeks of gestation in group 1 (Macrosomic fetuses; $n=$ 15)

\begin{tabular}{|c|c|c|c|c|}
\hline \multirow{2}{*}{ Parameters } & Relationship & $\begin{array}{c}\text { Correlation } \\
\text { Coefficient } \\
\text { value }(\boldsymbol{r})\end{array}$ & 95\% CI for r & P-value \\
\hline \multirow{2}{*}{ HbA1c \% } & $\begin{array}{c}27-28 \text { Weeks } \\
\text { of Gestation }\end{array}$ & -0.06735 & -0.4912 to 0.3844 & $\mathbf{0 . 7}$ \\
\cline { 2 - 5 } & $\begin{array}{c}36-37 \text { Weeks } \\
\text { of Gestation }\end{array}$ & 0.3886 & -0.06157 to 0.7102 & $\mathbf{0 . 0 8}$ \\
\hline \multirow{2}{*}{$\begin{array}{c}\text { UCA } \\
\text { (mm2) }\end{array}$} & $\begin{array}{c}27-28 \text { Weeks } \\
\text { of Gestation }\end{array}$ & 0.7340 & 0.4452 to 0.8903 & $\mathbf{0 . 0 0 0 2}$ \\
\cline { 2 - 5 } of Gestation & 0.7483 & 0.4611 to 0.8934 & $\mathbf{0 . 0 0 0 1}$ \\
\hline \multicolumn{7}{r|}{ CI: Confidence Interval, } \\
\hline
\end{tabular}

\section{DISCUSSION}

The relationship between umbilical cord components, $\mathrm{HbA} 1 \mathrm{c}$, and fetal macrosomia was evaluated at 27-28 gestational weeks. Macrosomic fetuses were compared to non-macrosomic fetuses. Umbilical cord area and Wharton's jelly values were statistically different for each group. Cord diameter, umbilical artery and vein area values were not statistically different between groups at this gestational time point. However, at 36-37 gestational weeks at the second examination, an assessment of the relationship between umbilical cord components and fetal macrosomia revealed that all umbilical cord parameters were statistically different for both groups when macrosomic fetuses compared to non-macrosomic ones, As regards the glycated hemoglobin, both groups did not differ significantly when compared the levels measured at 27-28 weeks of gestation. While, at 36-37 weeks of gestation, the macrosomic group had a higher HbA1c than group 2, which was statistically significant. The previously mentioned results were in agreement with those of a published research, at which the authors found a positive correlation between the umbilical cord area and the birth weight (g), especially when estimated at the beginning of the third trimester Birol et al. (2012) assessed umbilical cord components to predict fetal weight, and showed that there was a correlation between umbilical cord diameter area and fetal biometric parameters. In addition, some suggested that combination of these two methods should give more reliable results for estimating macrosomic fetuses. The study found that the relationship between umbilical cord thickness and fetal macrosomia was specific for diabetic patients, as it was non-significant in the non-macrosomic fetuses' subgroup. These data disagreed with the reported data of Birol et al. (2012) where the correlation was also significant for the control group. However, this might be due to the fact that their study design was based on cases controls design, while ours was including all as patients, no controls. 
In addition, some other studies have shown that the presence of a lean umbilical cord in the second trimester may cause low birth weight and results in more fetal distress in labor. Besides, they showed that umbilical cord diameter and area measurements are associated with increased fetal macrosomia (Proctor et al., 2013). Hadlock formula based on fetal biometric measurements that are still in use and maintains its importance. For all that, ultrasound-based fetal weight prediction is still insufficient. The positive predictive value of estimated fetal weight (EFW) varies between 60 and $79 \%$ (Proctor et al., 2013). They suggested that when EFW and umbilical cord area are combined together, the positive predictive value for macrosomic fetuses is significantly improved. In addition, the assessment of the umbilical cord area and its components does not seem to be influenced by gestational age or amniotic fluid volume. They reported through a period of approximately 2 weeks from ultrasound examination till delivery a results that were similar to our study.

In addition, Kamana et al. (2015) showed that delivery by cesarean section was higher in mother with macrosomic fetuses than non-macrosomic fetuses, which in turn is in agreement with our currently reported data. In the literature, postprandial blood glucose levels have been shown to be correlated with macrosomia.

\section{CONCLUSION}

Macrosomia is a cause of worst obstetric emergencies such as shoulder dystocia, birth asphyxia and postpartum haemorrhage. Shoulder dystocia cannot always be predicted accurately. However, predicting macrosomia can help to identify the population at risk of such complications. Several studies of sonographic measurement for predicting of fetal macrosomia were established. Umbilical cord thickness and fetal fat layer are good predictors of fetal macrosomia.

In the assessment of risk of macrosomia in addition to the ultrasonographic measurements the clinical risk factors must be considered. Further studies are needed to evaluate the clinical value of incorporating these soft tissue measurements in formulas for estimation of fetal weight.

\section{REFERENCES}

1. Athukorala C, Rumbold AR, Willson KJ and Crowther CA (2010): The risk of adverse pregnancy outcomes in women who are overweight or obese. BMC Pregnancy Childbirth, 10: 56-59.

2. Auger N, Park AL, Zoungrana H, Sing MF, Lo E and Luo ZC (2013): Widening inequality in extreme macrosomia between Indigenous and non-Indigenous populations of Québec, Canada. Aust N Z J Public Health, 37 (1): 58-62.

3. Barakat MN, Youssef RM and Al-Lawati JA (2010): Pregnancy outcomes of diabetic women: charting Oman's progress towards the goals of the Saint Vincent Declaration. Ann Saudi Med., 30: 265-270.

4. Beta J, Khan N, Khalil A, Fiolna M, Ramadan $G$ and Akolekar $R$ (2019): Maternal and neonatal complications of fetal macrosomia: systematic review and metaanalysis.. Ultrasound Obstet Gynecol., 54(3):308-318.

5. Birol B, Yeniel AO, Ergenoglu AM, Kazandi M, Akercan F and Sagol S (2012): The role of umbilical cord thickness and HbA1c levels for the prediction of fetal macrosomia in patients with gestational 
diabetes mellitus. Arch Gynecol Obstet., 285 (3): 635-639.

6. Cordero L, Paetow $P$, Landon $M B$ and Nankervis CA (2015): Neonatal Outcomes of Macrosomic Infants of Diabetic and NonDiabetic Mothers. J Neonatal Perinatal Med., 8(2):105-112.

7. Elessawy M, Harders C, Kleinwechter H, Demandt N, Sheasha GA, Maass N, Pecks $\mathrm{U}$ and Eckmann-Scholz C (2017): Measurement and evaluation of fetal fat layer in the prediction of fetal macrosomia in pregnancies complicated by gestational diabetes. Arch Gynecol Obstet., 296(3):445453.

8. He XJ, Qin FY, Hu CL, Zhu M, Tian CQ and Li Li (2015): Is Gestational Diabetes Mellitus an Independent Risk Factor for Macrosomia: A Meta-Analysis?. Arch Gynecol Obstet., 291(4):729-35.

9. International Diabetes Federation (2013): Global Guidelines for Type 2 Diabetes: Brussels, Belgium: IDF. International Association of Diabetes and Pregnancy Study Groups Consensus Panel (IADPSGCP). Diabetes Care, 33: 676-682.

10. Kamana KC, Shakya $S$ and Zhang $H$. (2015): Gestational Diabetes Mellitus and Macrosomia: A Literature Review. Ann Nutr Metab., 66 (suppl. 2):14-20.

11. Kuenen JC, Borg R, Kuik DJ, Zheng H, Schoenfeld D, Diamant M, Nathan DM and Heine RJ (2011): Does Glucose Variability Influence the Relationship Between Mean Plasma Glucose and HbA1c
Levels in Type 1 and Type 2 Diabetic Patients?. Diabetes Care, 34 (8): 1843-7.

12. Mandal D, Manda S, Rakshi A, Dey RP, Biswas SC and Amal BA (2011): Maternal Obesity and Pregnancy Outcome: A Prospective Analysis. J Assoc Physicians India, 59:486-489.

13. Marino L, Castaldi MA, Rosamilio R, Ragni E, Vitolo R, Fulgione C, Castaldi SG, Serio B, Bianco $R$, Guida $M$ and Selleri C (2019): Mesenchymal Stem Cells from the Wharton's Jelly of the Human Umbilical Cord: Biological Properties and Therapeutic Potential. Int J Stem Cells, 12(2): 218-226.

14. Proctor LK, Fitzgerald B, Whittle WL, Mokhtari N, Lee E, Machin G, Kingdom JC and Keating SJ. (2013): Umbilical cord diameter percentile curves and their correlation to birth weight and placental pathology. Placenta, 34(1):62-66.

15. Yessoufou A and Moutairou K (2011): Maternal diabetes in pregnancy: early and long-term outcomes on the offspring and the concept of "metabolic memory". Exp Diabetes Res., 21: 85-98.

16. Zhang J, Wu K, Xu X, Liu Z, Lin C, Wang Y, Yan $H$ and Yang $X$ (2015): Levels of insulin-like growth factors and their receptors in placenta in relation to macrosomia. Journal of Medical Genetics, 32(1):36-39. 


\section{دور قطر الحبل السرى ومستوي الهيموجلوبين السكرى فى الهي

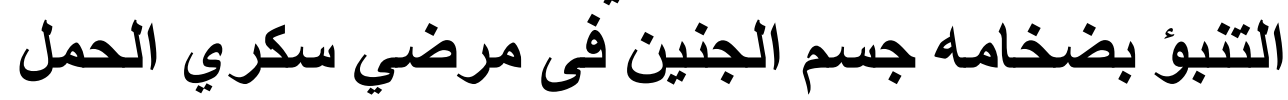

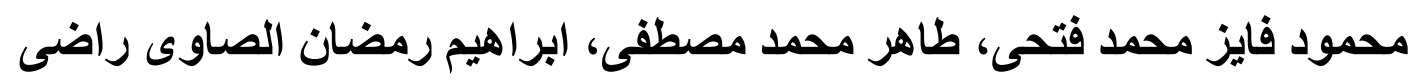
قسم التوليد وأمراض النساء، كلية الطب، جامعة الأزهر

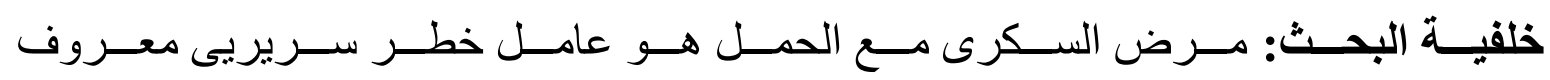

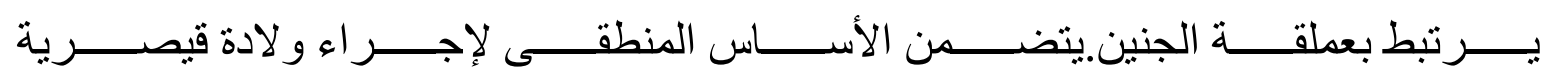

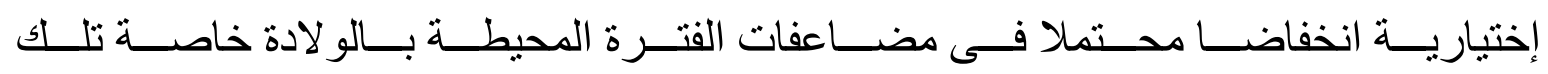
المنعلقة بعملقة الاجنة.

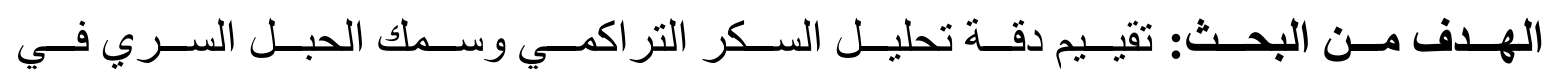
التنبؤ بعملقه الجنين في النساء الحو امل الدصابات بالسكري.

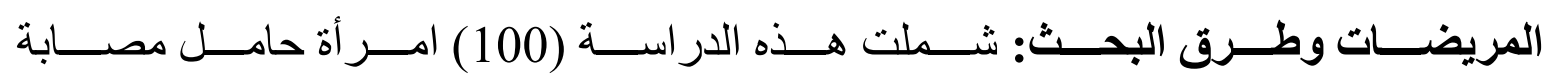

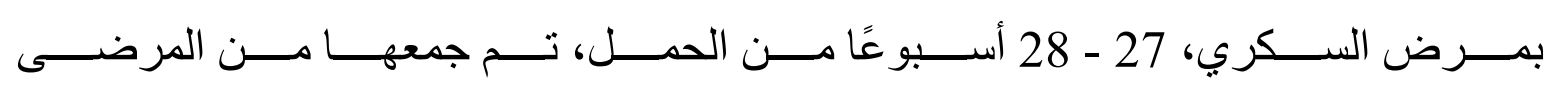

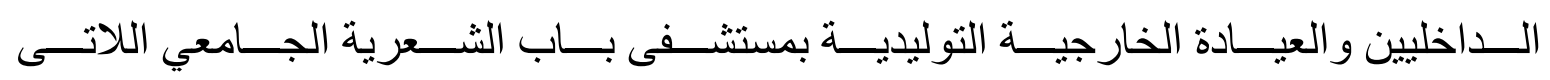

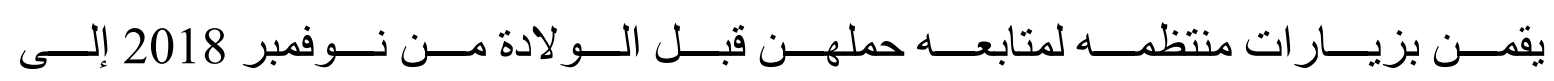

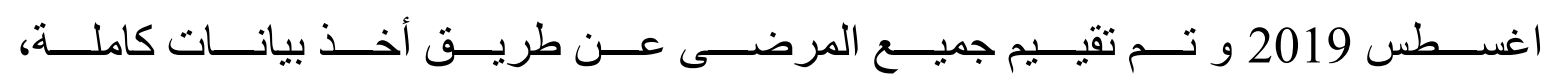

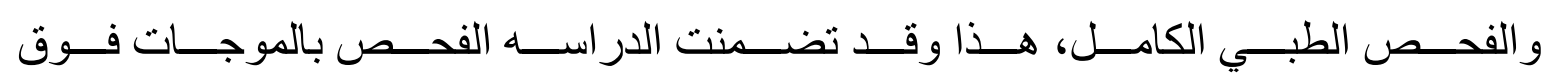

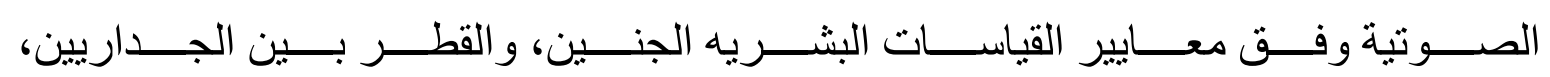

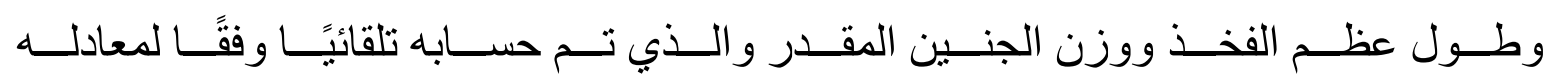
هادلوك.

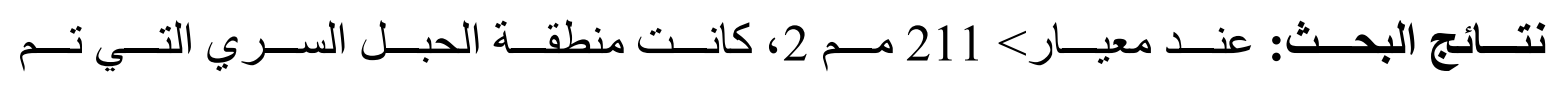

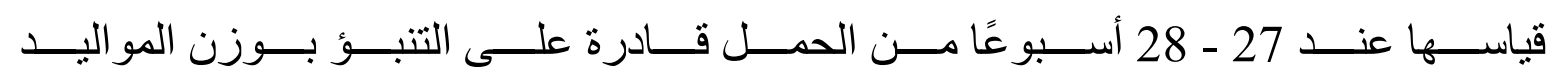

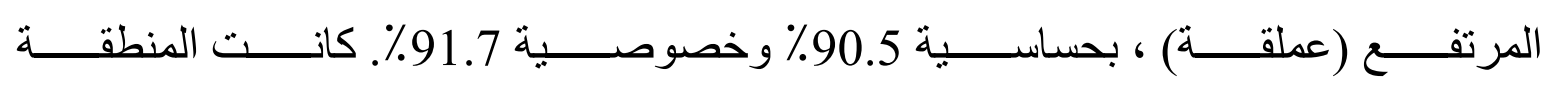

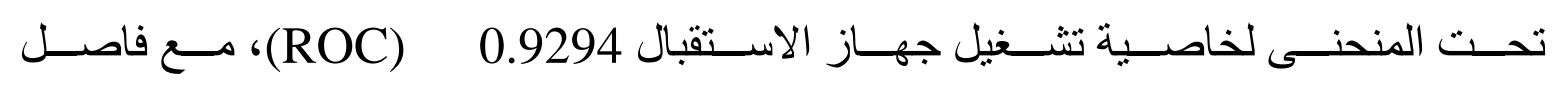

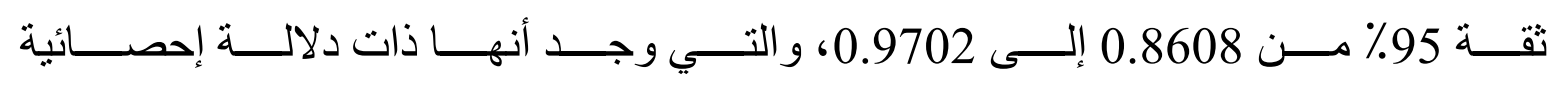

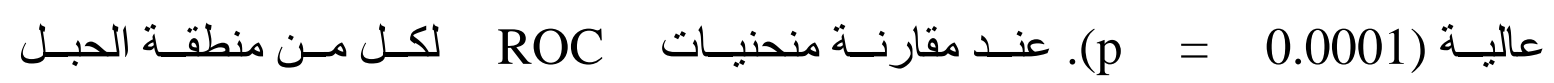




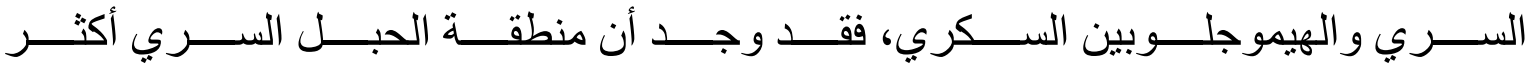

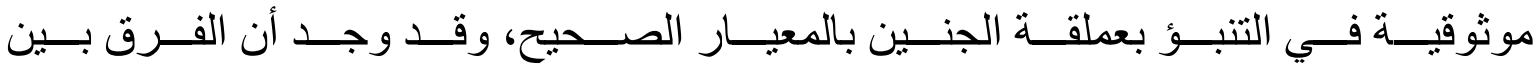
الكفاءة التنبؤية لكلا المعلمتين مرتفع إحصائيًا.

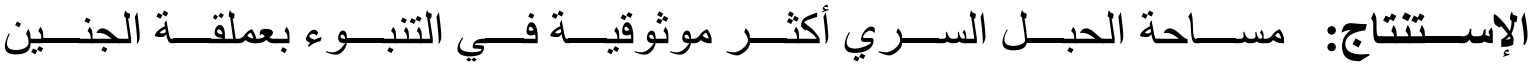

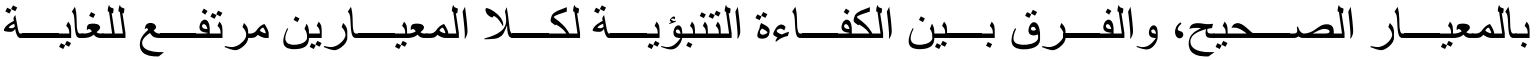

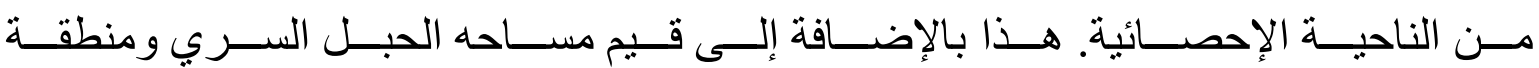

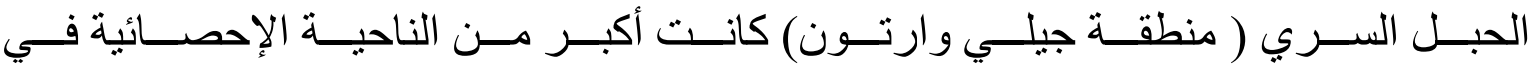

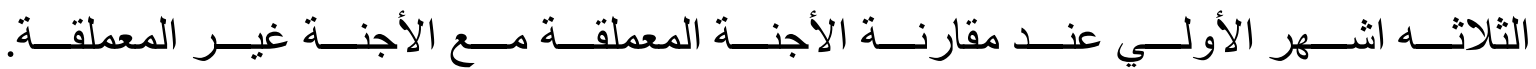

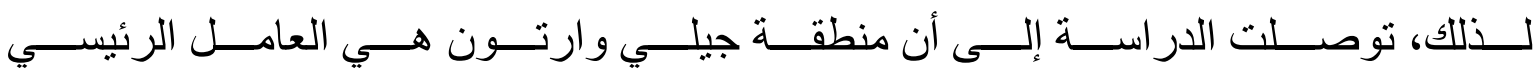
لسمك السرة المرتبط بتضخم الجنين. 